\title{
LA DIGNIDAD EN EL RETORNO DE LAS VÍCTIMAS DEL CONFLICTO ARMADO EN COLOMBIA
}

\section{THE DIGNITY IN THE RETURN OF THE VICTIMS OF THE ARMED CONFLICT IN COLOMBIA}

\author{
Felipe Andrés \\ Aliaga Sáez \\ Universidad Santo Tomás \\ felipealiaga@usantotomas. \\ Antonia \\ Chrysalide \\ Olmos Alcaraz \\ Duarte Castro \\ Universidad de Granada Universidad Santo Tomás \\ antonia@ugr.es \\ cri2709@gmail.com
}

edu.co

Resumen: Este artículo ${ }^{1}$ analiza el concepto de la dignidad en la migración de retorno, siendo un concepto que adquiere sentido propio en el contexto del retorno de las víctimas del conflicto armado colombiano. De esta forma el objetivo de la investigación ha sido identificar el tratamiento que se le ha dado a la dignidad en el marco normativo migratorio en el país. Como metodología se ha realizado un análisis documental de una serie de mecanismos regulatorios, así como en el relato de sus protagonistas, para lo cual se llevaron a cabo diez entrevistas a retornados vinculados al Foro Internacional de Víctimas (FIV) residentes en Bogotá. Se concluye que es necesario para construir estrategias de dignificación de las víctimas así como articular la información nacional con la proveniente de instrumentos internacionales y con estudios sobre dignidad. De tal manera que ofrezcan elementos prácticos para la construcción de una política integral, que cuente con el compromiso de los gobiernos así como de las personas retornadas y de la ciudadanía en general.

Palabras clave: Migración, exilio, derechos, reincorporación, Bogotá, dignidad.
Abstract: This article analyzes the concept of dignity in return migration, a concept that has acquired its own specific meaning within the context of the return to Colombia of victims of the Colombian armed conflict. The goal of the research has been to identify the treatment that has been given to the concept of dignity in the migratory normative framework in the country. The methodology for this study has involved1) a documentary analysis of a series of regulatory mechanisms, and 2) development of the story of its protagonists through a series of ten interviews with returning victims linked to the International Forum of Victims (IFV) resident in Bogota. It is concluded that to build strategies to dignify victims it is necessary to articulate national information with information coming from international instruments and with studies on dignity. In this way, it is possible to identify practical elements for the development of a comprehensive policy that has the commitment of governments as well as returnees and citizens in general.

Keywords: Migration, exile, rights, reincorporation, Bogotá, dignity.

1 Artículo producto de la investigación postdoctoral en estudios migratorios de Felipe Aliaga, denominada: "Análisis de los mecanismos de implementación de los acuerdos de paz en Colombia para la migración de retorno de las víctimas del conflicto armado", aceptada por el Instituto de Migraciones de la Universidad de Granada, bajo tutela y supervisión de Antonia Olmos. Contó con la activa colaboración de Jorge Enrique García, Diego Ballén Velázquez, Carla Rodríguez Portillo, y especialmente de Chrysalide Duarte, integrantes del Grupo de Estudios sobre Migraciones Internacionales y Vulnerabilidad (GEMIV) de la Universidad Santo Tomás Colombia. 


\section{Introducción}

En el último Informe sobre las Migraciones en el Mundo (2015) de la OIM, se menciona que habría unos 232 millones de migrantes internacionales. ACNUR, indica que a finales de 2015 serían 65,3 millones de personas desplazadas por la fuerza, de los cuales 21,3 millones son refugiados, 40 millones de desplazados internos y 3,2 millones de solicitantes de asilo. Las cifras de movilidad humana siguen en aumento y las condiciones pueden enfrentar a los migrantes a procesos de vulnerabilidad que planteen escenarios de reemigración o de retorno a sus países de origen, proceso que puede ser voluntario o forzado, como en el caso de las deportaciones.

Colombia es un país con una alta movilidad humana, tanto en el nivel del desplazamiento forzado interno como en lo que a movimientos migratorios hacia el exterior se refiere, producto del conflicto armado de más de cincuenta años. El último informe sobre desplazamiento forzado de ACNUR (2016:36) indica que "en Colombia, según el gobierno, había 7.4 millones de desplazados internos registrados al terminar 2016", siendo el país con mayor número de desplazados internos del mundo. Por otro lado se cuenta con aproximadamente 4.7 millones de migrantes en el exterior, según cifras publicadas por el programa de gobierno "Colombia Nos Une"2, desplazamientos que estarían motivados principalmente por la búsqueda de oportunidades laborales, la reunificación familiar y la educación superior.

Según ACNUR (2017), son 340.000 los colombianos refugiados en el extranjero producto del conflicto armado, especialmente en Ecuador, Venezuela, Panamá y Costa Rica. Sin embargo, también puede haber un número de personas que han tenido que salir forzadamente pudiendo encontrase en situación administrativa irregular porque no han solicitado y/u obtenido el estatus de refugiado. En este sentido según CODHES "hay un grupo importante y desconocido de colombianos que, habiendo migrado forzadamente hacia el exterior, se abstienen de solicitar el status de refugiado" (2017: 68). Las razones que pueden explicar dicha situación son varias, entre ellas que "consideren que su vida no está en riesgo; que el hecho victimizante no esté relacionado con su salida del país; que no tengan información al respecto de los mecanismos de protección internacional; y/o que prefieran mimetizarse con el resto de la población migrante, en tanto, el acceso a derechos no depende del estatus de refugiado" (2017: 68).

De esta manera las migraciones, internas e internacionales, son un aspecto de gran relevancia en el mundo y especialmente en Colombia, tanto si se trata de desplazamientos por causas económicas, como si hablamos de migración forzada. El tratamiento de este fenómeno por parte del Estado ha tenido una evolución desde la misma Constitución Política de 1991, en donde ya se establecían garantías de libre circulación en el territorio nacional, así como la posibilidad de entrar y salir de este; lo cual se conecta con el artículo 13 de la Declaración Universal de los Derechos Humanos, en donde se indica que "(1) Toda persona tiene derecho a circular libremente y a elegir su residencia en el territorio de un Estado. (2) Toda persona tiene derecho a salir de cualquier país, incluso del propio, y a regresar a su país"3.

2 La información no tiene fecha específica, y está publicada en: http://www.colombianosune.com/ informaciondeinteres/caracterizacion

3 Sin embargo, como sabemos, el artículo 13 de la Declaración Universal de los Derechos Humanos es un artículo que resulta incompleto, dado que aunque da cobertura para que las personas salgan de sus países no establece obligaciones para que los Estados receptores efectivamente acepten dichos flujos migratorios, quedando en manos de los mismos el establecimiento de los requisitos de entrada y permanencia. 
En 2009 se elaboró el Documento CONPES 3603, en donde se definen lineamientos para una política integral migratoria, considerando a los colombianos que viven en el exterior. En 2010 el tema migratorio adquiere importancia a través de dos importantes informes desarrollados por el Departamento Nacional de Planeación del Gobierno de Colombia: el informe "Visión Colombia II Centenario. 2019", que reconoce la importancia de generar vínculos con los migrantes en el exterior; y el "Plan de Desarrollo 2010-2014 "Prosperidad para Todos" donde se establece que el tratamiento migratorio es prioritario desde las diferentes instituciones.

En 2011 con la Ley 1465 se crea el Sistema Nacional de Migraciones, el cual también tendrá dentro de sus preocupaciones a las comunidades colombianas en el exterior, y es a través de esta Ley donde se establece la necesidad de generar "plan retorno" para los migrantes que regresen voluntaria o forzadamente. Posteriormente a través de la Ley de retorno 1565 de 2012 se crean una serie de incentivos para los retornados.

María Bedoya (2015), señala que a pesar de contar con un amplio marco jurídico en esta materia, los vínculos entre la política y los connacionales en el exterior son frágiles. En este sentido CODHES (2017:67), indica que "el Estado colombiano aún tiene problemas para garantizar los derechos de sus ciudadanos dentro del territorio. Por tal razón existen flujos forzados de ciudadanos colombianos hacia el exterior que se encuentran en necesidad de protección", los cuales además suman una serie de vulnerabilidades por los daños, la violencia y el desarraigo. Todo ello hace que el retorno de las víctimas se presente como una posibilidad todavía muy distante.

En el artículo "Imaginarios del retorno a Colombia posconflicto. Discursos de colombianos refugiados en Ecuador" (Aliaga et al., 2017), tras realizar una serie de grupos focales con población refugiada se concluye que debido al trauma dejado por el conflicto, el maltrato, la indiferencia de la sociedad civil, la desprotección estatal, la violencia y la situación de vulnerabilidad; la población se divide entre los que buscan refugio en un tercer país, los que se quieren adaptar a la sociedad ecuatoriana y quienes buscan retornar. En este sentido los autores indican que "el imaginario social puede determinar el retorno en la medida en que sus expectativas de regresar al país están cargadas de tensiones que no han logrado ser resueltas por la normatividad vigente en materia de migración y retorno" (2017:9).

Son diversas las fuentes sobre el total de retorno de colombianos en el exterior, según el informe de Victoria Prieto (2015) "El flujo acumulado de retornados entre 2001 y 2008 asciende a 319.010 personas de acuerdo a estimaciones de Mejía (2010)" (2015:18). Por su parte, Margarita Echeverri y Carol Pavajeau (2015) indican que según la encuesta Enmir de 2009, la cantidad de retornados se calculaba en 534.943. En un informe de Cancillería presentado en 2017, las cifras indican que desde 2013 a 2016 se presentaron en el Registro Único de Retornados (RUR) 7.608 solicitudes y se aprobaron 5.013, de las cuales 2.795 retorno laboral; 2.205 retorno productivo; 1.424 humanitario o por causa especial; 645 solidario $^{4}$ y 539 ninguno. Sin embargo, no se desagrega las aprobadas en cada tipo.

La firma de los acuerdos de paz abre la posibilidad de que muchos colombianos que se encuentran en el exterior en condición de refugio puedan perder su estatus, ya que los países que acogen población refugiada pueden argumentar que al haber

$4 \quad$ Este es el que acoge a las víctimas del conflicto armado. Es posible que posterior a la firma del acuerdo de paz y durante el proceso de posconflicto se produzca un aumento en el retorno de las víctimas. 
concluido el conflicto, la condición de refugiado no tendría razón de ser. Así también personas exiliadas que se encuentran en un limbo administrativo puedan considerar la posibilidad de retornar. En este sentido se hace prioritario estudiar las condiciones y los mecanismos políticos que se estén generando hacia este sector de población, que se puede encontrar en situaciones de alta vulnerabilidad.

Para este trabajo se ha tomado como eje de análisis el concepto de la dignidad en el retorno de las víctimas, las cuales se encuentran en un alto nivel de vulnerabilidad y requieren un acompañamiento efectivo, tomando el concepto de dignidad como una condición necesaria propuesta por ACNUR (1996) en la triada de retorno digno, seguro y voluntario. Aspecto muy presente desde la misma Declaración Universal de los Derechos Humanos, en su artículo primero "Todos los seres humanos nacen libres e iguales en dignidad y derechos"; y como lo plantea el Manual regional "Derechos humanos de la personas migrantes" (2017:17), los derechos humanos "todos se refieren a la dignidad intrínseca de todas las personas". De esta forma el objetivo de este artículo es analizar cómo el concepto de dignidad en el retorno de las víctimas adquiere contenido a través del panorama normativo nacional en materia migratoria relacionada con los colombianos en el exterior; y en segundo lugar, desde el discurso de los protagonistas del retorno, lo cual se complementará con una serie de aportes conceptuales, para poder identificar cuáles son los elementos que definirían la dignidad en este contexto particular, acotando en parte la polisemia de la categoría con el fin de que se pueda lograr cierta aplicabilidad práctica de las dimensiones identificadas.

\section{Un acercamiento al concepto de dignidad}

No existe una definición única y consensuada con respecto al significado del concepto de dignidad humana, por lo cual se tomarán algunas ideas que puedan ser orientadoras en cuanto al contexto de análisis. Como mencionan Bohórquez y Aguirre (2009: 41), "la importancia teórica y práctica del concepto de <<dignidad humana>> es difícil de negar. Se trata además de una noción que puede ser abordada desde una gran variedad de perspectivas y disciplinas pues es una idea que tiene aplicaciones en diversos ámbitos de la vida humana [...]". Esta descripción del concepto nos permite entender que dependerá en dónde y desde dónde lo estemos observado y pensando su sentido específico. De esta forma el enfoque adoptado no puede sino estar inserto en una lectura interdisciplinaria desde las ciencias sociales, así como en un período histórico determinado y en donde el ser humano migrante se ve enfrentado a una serie de vulneraciones de sus derechos humanos, lo cual se busca visibilizar.

La literatura existente sobre el concepto de dignidad relaciona de manera muy intensa la misma con la formulación de los derechos humanos. Sin embargo no podemos dejar de considerar que dicho concepto cuenta con "milenarias raíces históricas, antropológicas y religiosas [...], (y) su historia como uno de los valores universales sobre los que se basan los derechos humanos es relativamente reciente" (Bohórquez y Aguirre, 2009: 41). A este respecto podemos encontrar trabajos críticos que, ante la denuncia sobre la parcialidad que implica que los derechos humanos sean una formulación realizada desde occidente para occidente:

"[...] muchas han sido las críticas que se han hecho en torno a tales derechos. Entre estas críticas está la acusación de que los mismos constituyen una nueva forma de colonialismo occidental al desconocer la pluralidad cultural e histórica 
que nos caracteriza como seres humanos. [...] desde esta perspectiva los derechos humanos han servido como discurso ideológico para intervenir en la realidad a partir de los intereses de las clases sociales que detentan el poder y de la ideología y la cultura dominantes" (Gándara, 2014:77).

Entenderían que la idea de dignidad, asimismo, implica el riesgo de focalizar solo aquellas realidades y procesos que desde posiciones occidentalocéntricas se estimen convenientes, impidiendo con ello la convergencia con otras luchas por la dignidad surgidas fuera del marco de los derechos humanos. A este respecto Joaquín Herrera (2005: 91), menciona el hecho de que "si no sabemos posicionarnos ante ella y asumir disposiciones críticas frente a sus posibles interacciones ¿cómo hacer para seguir luchando por la dignidad humana en nuestro espacio cultural occidental? ¿Cómo hacer para converger con otras formas de lucha por la dignidad humana que sólo ven en los derechos humanos la justificación ideológica de los horrores del colonialismo?". Los derechos humanos "parten de [una] idea de dignidad humana, que (...) se apoya en una concepción de la naturaleza humana individual, autosostenible y cualitativamente diferente de la naturaleza no humana" (Santos, 2014: 33). La cuestión es ver que la naturaleza humana debe ser interpretada desde el contexto cultural, en ese sentido, la idea de dignidad puede ser incluso apropiada como un mecanismo de justificación de intervenciones violentas con el fin de pacificar y "devolver la dignidad" a las personas, en algunos casos arrasando con la naturaleza, o dejando esteras de desolación que no hacen más que mantener la dignidad extraviada.

Por su parte, Antoni Jesús Aguiló (2009: 180) plantea que "la Declaración Universal de los Derechos Humanos establece que todos los seres humanos son iguales en dignidad y derechos. Sin embargo, existen muchas y poderosas razones para cuestionar la supuesta universalidad atribuida a los derechos humanos", y por consiguiente del concepto de dignidad humana. En otras palabras, el etnocentrismo que opera bajo el carácter occidental de los derechos humanos puede impedir tanto que la noción de dignidad humana que subyace a los mismos se haga extensible a todos, como que conceptos de dignidad otros sean considerados y/o reconocidos. Este aspecto justifica aún más la búsqueda y análisis de cómo se está enunciando el concepto de dignidad, ya que si forma parte de la naturaleza y de los derechos humanos, de manera correlacionada nos está mostrando los componentes de otros aspectos que estarían en una matriz elemental de cómo debe estar constituido el ser humano.

Bohórquez y Aguirre (2009: 42), en esta misma línea, plantean una discusión sobre las tensiones y contradicciones que surgen al intentar definir este concepto. Los autores se refieren a los cuestionamientos sobre si la dignidad humana es inherente a los seres humanos o es consensuada y aprobada por los Estados; si es un concepto abstracto o si se puede definir en relación con aspectos concretos; y si la dignidad humana es un valor universal o particular dependiendo del contexto. En este sentido, partimos de la idea de que al estar posicionada como un vector clave de qué es la propia humanidad, se debe entender en relación a una serie de niveles, por un lado los niveles internacionales o globales, que permitan realizar acciones de gobernanza, así como ajustado a una serie de principios de qué se entiende por un ser humano digno, en cuanto que ya se vincula directamente con el cumplimiento de los derechos, cuestión que nos lleva a un nivel diferenciado en lo nacional o local, ya que allí se pueden identificar particularidades, basadas en aspectos culturales propios de cada contexto, que requerirán el contraste de significados entre los diferentes sectores, ya sea el ámbito político o la sociedad civil. 
Javier De Lucas (2010: 73) a este respecto cuestiona la utilidad misma del concepto de dignidad en tanto que está íntimamente ligado a otras nociones, como autonomía individual e igualdad, que aportan mayor precisión y claridad sobre las ideas referidas:

“(...) la noción de dignidad sería superflua o sustituible con ventaja porque no se advierte qué puede añadir a otras nociones más precisas, como las de autonomía o la de igualdad/universalidad. A pesar de todos los intentos de añadir concreción y utilidad al concepto de dignidad, de tratar de presentarla como algo más que una noción abstracta, si no vacía, y enfatizar la función de fundamentación, en tanto que la dignidad significa la atribución de un valor intrínseco que convierte el ser humano en un fin en sí mismo, en valor; el hecho es que este principio no permite ir más allá. De hecho cuando se trata de concretar en qué consiste la dignidad, la mayor parte de las veces se apela a dos nociones: la autonomía individual y la universalidad-la radical igualdad-de todos los seres humanos, de todos aquellos que pertenecen al género humano".

La respuesta a la limitación del concepto, en relación a la posibilidad de ser sustituido, como indica De Lucas, dependerá de cómo el mismo concepto sea comprendido o posicionado en cuanto a un determinado sistema (legal, político, religioso, económico, etc.) o a un grupo de individuos específico, de esta forma, puede tomar una amplitud que no se puede reducir sin antes indagar en los significados que se le otorguen. Pudiendo ser comprendido como un eslabón del sentido de la existencia de quienes lo reclamen como propio en diferentes sociedades, culturas y tiempos.

Desde un enfoque crítico, la perspectiva de Boaventura de Sousa Santos (1998: 356), puede contribuir a establecer un punto clave en cuanto a la reflexión sobre el concepto:

"Todas las culturas tienen concepciones de la dignidad humana, pero no todas las conciben como derechos humanos. Es, por tanto, importante aprehender las preocupaciones isomórficas entre diferentes culturas. Nombres, conceptos y visiones de mundo diferentes pueden transmitir preocupaciones y aspiraciones similares $y$ mutuamente inteligibles. [...] todas las culturas son incompletas y problemáticas en sus concepciones de la dignidad humana. Esta incompletitud deriva precisamente del hecho de que hay una pluralidad de culturas. [...] todas las culturas tienen versiones diferentes de la dignidad humana, algunas más amplias que otras, algunas con un mayor compás de reciprocidad que otras, algunas más abiertas a otras culturas que otras".

El autor se pregunta a este respecto "¿Qué otros lenguajes de la dignidad humana existen en el mundo?" más allá del lenguaje de los derechos humanos; y si dichas gramáticas pueden ser compatibles con los derechos humanos (Santos, 2014: 23).

Por lo tanto, las voces frente a la dignidad pueden ser diferentes en relación a como se observa el vivir en dignidad, es decir más allá del enfoque de derechos que es importante o necesario para que un ser humano sienta que tiene una vida plena. Es en este sentido que se conecta con los requerimientos de un buen vivir, o de la satisfacción de necesidades que nos permitan alcanzar la felicidad; asumiendo con todo esto que habrá fuerzas discursivas que puedan querer dominar o construir imaginarios dominantes sobre qué es suficientemente digno y que no. Por lo tanto la dignidad será también un esquema de conflicto de intereses que se trasladará a qué es más o menos humano, y qué es ser feliz o infeliz. 
Resulta sugerente la perspectiva práctica de la dignidad, planteada por la investigadora colombiana Ilva Myriam Hoyos (2005: 187). Para la autora la dignidad, así como tener un contenido universal, "también requiere de medios a través de los cuales su contenido pueda expresarse o formularse en una sociedad determinada". De esta forma la dignidad en su dimensión práctica requiere evaluar las relaciones intersubjetivas presentes en un contexto determinado, estableciendo criterios orientadores, reglas o fórmulas, en donde cada situación debe evaluarse específicamente. Hoyos plantea que la dignidad se enmarca en el respeto y el reconocimiento por el otro, afirmando que "el respeto es el reconocimiento de la propia dignidad y de la dignidad de los otros" (191). El respeto implicaría aceptar a la persona en una comunidad y reconocerlo, en cuanto apertura hacia los demás; y el reconocimiento implicaría una doble dimensión: "la aceptación de lo propio y también la aceptación de lo común que se da tanto en la persona como en las personas" (195). La dignidad se constituiría como un bien común, "es el máximo bien de la sociedad" (198). Por lo tanto, la dignidad debería ser analizada bajo ciertas condiciones contextuales, quedando de manifiesto la importancia del reconocimiento de la dignidad personal, pero también dentro y en relación a la comunidad.

En este mismo sentido, Dorando Michelini (2010: 41-42) expone una idea de dignidad bajo la perspectiva de I. Kant, en la que "concibe la $<<$ dignidad $>>$ como un valor intrínseco de la persona moral, la cual no admite equivalentes (...) y como una atribución propia de todo ser humano, no en tanto que individuo de la especie humana, sino que en tanto miembro de la comunidad de seres morales". De esta forma la idea de comunidad toma mucha relevancia como punto de partida de la dignidad, cuestión que abre un amplio margen de interpretación dentro de una misma sociedad. El lazo social en búsqueda de la unidad y cohesión puede establecer mecanismos de comprensión y significación o resignificación de valores, que pueden llevar al reconocimiento de la dignidad bajo nuevos códigos éticos o morales y otros principios de cooperación entre las personas. Habermas entiende que "únicamente sobre la base de una colaboración recíproca, los derechos fundamentales pueden cumplir la promesa moral de respetar por igual la dignidad humana de cada persona" (Habermas, 2010: 9).

Como vemos, son muchas y diversas las interpretaciones en torno al concepto de dignidad humana. Siendo así, de todos los elementos señalados consideramos pertinente resaltar que -para efectos de este artículo- se coincide con el hecho de que el "el concepto de dignidad humana es una expresión eminentemente ética. [...] En general, el concepto de dignidad humana remite al valor único, insustituible e intransferible de toda persona humana [...]" (Michelini, 2010: 42-43), lo cual se debe establecer de manera práctica (Hoyos, 2005) acorde a las necesidades de las personas y de los contextos nacionales e internacionales, pero también asegurando su cumplimiento por parte de los Estados y los propios sujetos.

\section{Metodología}

El proyecto contó con una primera fase que consistió en análisis documental, en donde se buscó identificar el ámbito del retorno, su vinculación con la dignidad y con las víctimas. Se realizó análisis de contenido del documento CONPES 3603 de 2009; la Ley 1465 de 2011; Ley 1565 de 2012; Ley 1448 de 2011; Acuerdo de Paz de 2016; Manual Repatriación Voluntaria: Protección Internacional (ACNUR, 1996) y el Manual de Reasentamiento del ACNUR (2011). 
El trabajo de campo se realizó en el mes de mayo y junio de 2017 y consistió en diez entrevistas semi-estructuradas a personas retornadas víctimas del conflicto armado, mayoritariamente exiliados políticos, que forman parte del capítulo retorno del Foro Internacional de Víctimas (FIV), se entrevistó a siete mujeres y tres hombres. Las personas actualmente se encuentran radicadas en Bogotá. Se estableció contacto con ellas gracias al apoyo de la Comisión sobre Migraciones Forzadas, Exilio y Reconciliación (CER) y la Consultoría para los Derechos Humanos y el Desplazamiento (CODHES). El análisis fue de tipo hermenéutico, tratando de interpretar y captar significados latentes tanto en los documentos revisados como en las entrevistas realizadas.

\section{La dignidad en el marco normativo colombiano: de la au- sencia a una tímida emergencia}

Dentro de la etapa de análisis documental del proyecto hemos considerado fundamental rastrear la aparición del retorno digno en los marcos normativos nacionales y hemos descubierto que existe un fuerte vacío y falta de articulación en relación a esta materia específica.

La revisión de la normativa migratoria en Colombia demuestra que es un concepto que no ha tenido mayor cabida. Sin embargo, es importante mencionar en este apartado el hecho de que la definición de retorno digno de los refugiados a nivel internacional existe como tal desde 1996. Es desde entonces que el Alto Comisionado de las Naciones Unidas para los Refugiados (ACNUR) publica el Manual Repatriación Voluntaria: Protección Internacional, actualizado en 2011 como Manual de Reasentamiento del ACNUR, el cual introduce diferentes sutilezas conceptuales en la forma de enunciar la dignidad, que pasa de referirse a los refugiados en cuanto a posibles situaciones a establecer de manera radical negaciones o afirmaciones. Por ejemplo, en la definición de 1996 se indica que los refugiados "no sean maltratados", y en 2011 dicha idea se enuncia aludiendo a que los refugiados "no son maltratados". En otro caso se pasa de decir que los refugiados "no sean separados" arbitrariamente de sus familiares, a afirmar -nuevamente en tono de negación- que "no son separados"; de igual manera el que "sean tratados con respeto" (por sus autoridades nacionales) en la nueva definición se plantea como "son tratados con respeto", es decir de forma afirmativa. Sin embargo quizás una de las diferencias más rotundas es la enunciación en torno a los derechos. En la primera versión se expone "incluso restituyendo sus derechos", mientras que en la nueva definición se afirma que "gozan de la plena restitución de sus derechos". De esta manera habríamos de entender que el retorno digno asegura la restitución de derechos de forma sine qua non.

Como vemos este manual entrega una serie de elementos "prácticos" (Hoyos, 2005) para una definición de la dignidad en el retorno de las víctimas, en donde también aparece la idea del retorno sin condiciones o al propio ritmo de las personas que están regresando de forma espontánea. Es decir de forma voluntaria.

A pesar de ser esta una referencia internacional en la comprensión de la dignidad en el retorno, que incluso se desarrolla antes del documento CONPES de 2009, no se observa que haya sido tomado en consideración para la elaboración del marco jurídico colombiano, hasta llegar a la Ley de víctimas y al Acuerdo de paz. Ello es indicativo de la falta de coordinación en las formas de gobernanza a nivel nacional e internacional, a pesar de que como indica Antonio Gutiérrez "Desde su elaboración en 1996, el Manual de Reasentamiento ha sido utilizado por cientos de funcionarios 
del ACNUR y sus socios para ayudar a cientos de miles de refugiados a comenzar una nueva vida en nuevos países. Es una herramienta indispensable para una solución indispensable" (ACNUR, 2011: 1).

En Colombia el primer documento que hay que tomar en consideración en materia migratoria es el CONPES 3603 de 2009, el cual presentó una política integral migratoria, en donde se integraron orientaciones para la atención y protección de los colombianos en el exterior; y se plantea por primera vez el retorno de los colombianos, por ejemplo en el caso de quienes han adquirido formación en el exterior, como es el caso de estudiantes, docentes e investigadores. Aquí aparece enunciado la necesidad de elaborar, coordinar e implementar un plan retorno, pero en ninguna parte aparece el concepto de dignidad como una característica del retorno.

La Ley 1465 de 2011 del 29 de junio de 2011, "por la cual se crea el Sistema Nacional de Migraciones y se expiden normas para la protección de los colombianos en el exterior", también incluye el tratamiento del retorno de los migrantes. En su artículo $4^{\circ}$, apartado quinto, aparece por primera vez mencionado que se fortalecerán acciones y mecanismos de carácter político y técnico para mejorar las condiciones y la calidad de vida de los colombianos en el exterior y de sus familiares, y dentro de estas se encuentra la asistencia al retorno. El artículo $8^{\circ}$ indica que se formulará un plan retorno, el cual debe incluir una serie de alianzas interinstitucionales y de cooperación; política que debe conducir a la plena reinserción de los retornados. En ninguna parte de este marco legal se deja de manifiesto el concepto de dignidad.

Es importante mencionar que dentro del marco legal vigente se aprueba la Ley 1565 del 31 de julio de 2012, "por medio de la cual se dictan disposiciones y se fijan incentivos para el retorno de los colombianos residentes en el extranjero", sin embargo, tampoco en ninguno de sus artículos menciona el concepto dignidad. Esta Ley establece cuatro tipos de retorno: productivo, laboral, humanitario o por causa especial y el solidario. Este último orientado a las víctimas del conflicto armado, el cual aparece articulado con la Ley 1448 de 2011, "por la cual se dictan medidas de atención, asistencia y reparación integral a las víctimas del conflicto armado interno y se dictan otras disposiciones".

La Ley 1448 en el artículo 28, que establece el derecho de las víctimas, en el apartado 8 indica que las víctimas tienen el "derecho a retornar a su lugar de origen o reubicarse en condiciones de voluntariedad, seguridad y dignidad, en el marco de la política de seguridad nacional". Por primera vez aparece la dignidad como dimensión que debe ser una característica del retorno, en el artículo 73, en cuanto a los procesos de restitución de las víctimas, en el apartado 4.Estabilización, indica que "Las víctimas del desplazamiento forzado y del abandono forzado, tienen derecho a un retorno o reubicación voluntaria en condiciones de sostenibilidad, seguridad y dignidad". Esta Ley establece en el Capítulo II, dentro de sus principios generales, en el artículo $4^{\circ}$. DIGNIDAD, que "el fundamento axiológico de los derechos a la verdad, la justicia y la reparación, es el respeto a la integridad y a la honra de las víctimas. Las víctimas serán tratadas con consideración y respeto, participarán en las decisiones que las afecten, para lo cual contarán con información, asesoría y acompañamiento necesario y obtendrán la tutela efectiva de sus derechos en virtud del mandato constitucional, deber positivo y principio de la dignidad". En este sentido por medio de esta Ley se busca estar en concordancia con tratados y convenios internacionales sobre Derecho Internacional Humanitario y Derechos Humanos ratificados por Colombia, buscando favorecer la dignidad y la libertad de la persona humana (Art. 27). Sin embargo, la limitación de esta Ley es que no deja de manifiesto que se refiera 
a las víctimas que se encuentran desplazadas extraterritorialmente, sino más bien a los desplazados internos, aunque ya deja sentada una serie de criterios que van otorgando cuerpo al concepto.

En el Acuerdo de paz "Acuerdo final para la terminación del conflicto y la construcción de una paz estable y duradera" (2016), aparece por primera vez de forma explícita el retorno digno para las víctimas que se encuentran en exterior, en el punto 5.1.3.5, "Procesos colectivos de retornos de personas en situación de desplazamiento y reparación de víctimas en el exterior". En este documento aparecen las tres características que debería tener el retorno, a saber, la seguridad, dignidad y voluntariedad. En este caso la dignidad se relacionaría con el fortalecimiento del programa de reconocimiento y reparación de víctimas en el exterior, incluyendo refugiados y exiliados victimizados con ocasión del conflicto. Todo ello mediante la puesta en marcha de planes de "retorno acompañado y asistido", bajo "condiciones dignas de acogida" a través de la coordinación de estos planes con la oferta institucional específica para garantizar progresivamente el acceso a derechos básicos, al empleo digno, vivienda, salud y educación en todos los niveles según las necesidades de cada quien. También se contempla la reubicación en lugares desde donde tuvieron que partir, respetando la voluntad de la víctima; y diferentes medidas para impulsar y promover el regreso de exiliados y demás colombianos que abandonaron el país por causa del conflicto.

Como vemos la dignidad se traduce en una serie de "condiciones" para su cumplimiento, en línea -podríamos decir- con lo que Hoyos (2005) establece como una perspectiva práctica de la dignidad que "proporcione medios [para que] su contenido pueda (...) formularse en una sociedad determinada" (187). De esta manera para que el retorno sea digno habrá que acompañar cada uno de estos aspectos y verificar su cumplimiento, tarea que debería ser abordada de manera interdisciplinaria (Bohórquez y Aguirre, 2009) para que su lectura no se vuelva limitada (De Lucas, 2010). En este caso, se amplía a una posición que encuentra asidero en la devolución u otorgamiento de mecanismos de apropiación o reapropiación de recursos simbólicos y materiales para ir recuperando la dignidad, elementos que deben ser reclamados en relación a lo legal y culturalmente válido (De Sousa, 1998) en el contexto colombiano.

Pero también, como hemos mencionado anteriormente, es una tarea conjunta entre autoridades, la ciudadanía en general y las víctimas, en el sentido en que es importante que éstas, en la medida de lo posible, hagan exigibles sus derechos, y que la lucha por obtener un reconocimiento no se quede sólo en el papel, pues "la historia de nuestros pueblos demuestra no pocos casos en que generosas movilizaciones sociales cesan una vez alcanzada la meta de un marco jurídico capaz de recoger demandas sociales específicas, desconociendo que tal logro, siendo sin duda necesario, es absolutamente insuficiente si no se mantiene la presión social para que las transformaciones necesarias se lleven a cabo y se sostengan en el tiempo" (Gándara, 2014). Sin embargo, frente a estos elementos es importante saber cuál es el posicionamiento (Herrera, 2005) de las propias víctimas.

El análisis permitió constatar que es difícil establecer vínculos entre los conceptos de dignidad analizados en este artículo y la normatividad colombiana en relación al retorno de las víctimas, pues si bien se evidencia una tímida emergencia del concepto que ha incrementado conforme se aprueban nuevas leyes o decretos, es importante que este concepto responda a las necesidades reales de las víctimas, ya sea las que se encuentran en el exterior, las que desean retornar o las que ya han regresado al país; y más allá de la ausencia conceptual, el verdadero vacío puede ser la falta de mecanismos que garanticen el retorno digno que se enuncia. 


\section{La dignidad desde las víctimas retornadas}

En el relato de los retornados se han identificado una serie de elementos que se ubican en el plano de la subjetividad como el campo semántico con mayor potencia. Emergen aspectos sensibles, tales como la reparación moral frente al daño causado por el conflicto, lo cual se relaciona con una transgresión al honor de las personas exiliadas, considerando el exilio como una situación indecorosa que se puede entender como una ruptura de la idea de la persona misma, en cuanto ser humano o miembro de una comunidad de seres morales (Michelini, 2010).

"La dignidad es el valor de la persona, cuando llegamos acá es como un segundo exilio, es necesario reparar, porque tú te fuiste y te fuiste contra tu voluntad" (Mujer, entrevista \#3, 15 de mayo de 2017).

"La dignidad yo la entendería como la posibilidad de poder regresar en condiciones decentes, en términos económicos, sociales, sin la posibilidad de sufrir de un estigma por haber salido del país por términos políticos, por haber sido refugiada, sobretodo esa reivindicación, aun cuando uno ha salido por afirmaciones que no son ciertas que se les haga una reparación moral o como lo quieran llamar" (Mujer, entrevista \#8, 30 de mayo de 2017).

"La dignidad es el honor como persona, la valoración como igual" (Mujer, entrevista \#4, 20 de mayo de 2017).

Lo anterior implica que es necesario recuperar la dignidad que se ha extraviado debido al conflicto armado, en donde se vuelve fundamental alcanzar el perdón por el exilio y recuperar la dignidad a través de procesos de reconocimiento y respeto, corroborando la idea de Hoyos (2005); generando lo que una de las personas entrevistadas define como una memoria digna; disponiendo de condiciones decentes de vida y evitando la estigmatización por ser retornado víctima del conflicto. En este sentido la dignidad se transforma en una lucha (Herrera, 2005), ya que los retornados buscan recobrar una serie de condiciones necesarias para poder sentir que tienen nuevamente una reincorporación en la sociedad colombiana, la cual tuvieron que abandonar por la fuerza. También se sigue ampliando el concepto en la necesidad de encontrar los aspectos propios al contexto cultural (Santos, 1998), ya que son las mismas víctimas las que requieren sus propias condiciones de humanidad.

"Los exiliados en Colombia tampoco tuvieron dignidad nunca, pobres sin oportunidades, ni política, ni social, ni económica, entonces ellos tienen la dignidad extraviada" (Mujer, entrevista \#4, 20 de mayo de 2017).

"Yo creo que la recuperación de la dignidad, es la única que puede lograr que esa condición de víctima se torne difusa” (Mujer, entrevista \#4, 20 de mayo de 2017).

En ese sentido se entiende que será fundamental recuperar el trayecto de vida, así como la experiencia adquirida fuera del país. Esto, asimismo, ofrece una serie de elementos de sentido que se relacionan con la búsqueda de aspectos concretos en torno a la dignidad (Bohórquez y Aguirre, 2009), anclados a los contextos y vivencias de quienes le dan contenido propio al concepto. Las víctimas del conflicto han tenido que experimentar un proceso de migración forzada enfrentando lo que podemos identificar como una expulsión de su territorio, principalmente por motivos de violencia y despojo (Delgado, 2014), lo cual sin duda ofrece una experiencia diferenciada en cuanto proceso migratorio, y marca un precedente en la manera de significar la dignidad. 
"Construir un proyecto de vida, que tengan las condiciones adecuadas, derecho a ese pedazo de país que ha construido, poderlo regresar, volver con sus cosas, con su vida construida en el exterior, reconocida, bienes no solo materiales, sino espirituales, porque la gente que regresa con un conocimiento de vida, que es una experiencia enriquecedora" (Mujer, entrevista \#6, 29 de mayo de 2017).

"Unas condiciones dignas consisten en que el momento que tu regreses se pueda restablecer tu proyecto de vida, esa es la parte más importante, me parece, que puedas desarrollar tu proyecto de vida en tu país, de donde tú no te quisiste ir" (Mujer, entrevista \#2, 11 de mayo de 2017).

Otro tipo de medios a través de los cuales se expresa la dignidad es en términos estrictamente materiales (Hoyos, 2005). Las personas entrevistadas señalan la necesidad de contar con condiciones socioeconómicas para el sustento del retorno, a través de la satisfacción de necesidades básicas tales como vivienda, empleo y salud, lo cual supone tener apoyo durante el proceso de reincorporación y reparación. Este plano se corresponde con el goce de derechos básicos que debería otorgar la dignidad humana, lo que responde a un proceso de soporte necesario para poder tener una vida con las condiciones para satisfacer necesidades primordiales. Ello puede ser considerado también como parte del aspecto moral (Michelini, 2010) de la comunidad nacional, para lo cual debería existir colaboración de diferentes sectores de la sociedad (Habermas, 2010).

"Retornar a su país y poder suplir, cumplir, con todas las necesidades básicas, una vivienda, trabajo, salud, lo base que no se ha podido cumplir" (Mujer, entrevista \#5, 26 de mayo de 2017).

"Hay unos derechos materiales que se tienen que garantizar, algunas personas tuvieron que abandonar sus tierras, vivienda, trabajos, sus organizaciones, ¿cómo hacer para el momento de retornar?, no va a poder a retornar en el mismo estado de cuando se fue, pero sí que tenga unas oportunidades para retomar su proyecto de vida en el país; entonces eso es necesario, el reconocimiento colectivo. Si estaba en una edad laboral poderte restablecer, tener un trabajo digno, además de unas condiciones de apoyo para retomar tu vida, entonces eso requiere un apoyo" (Mujer, entrevista \#2, 11 de mayo de 2017).

"Retorno digno yo lo miro que tú puedes llegar, que tú puedes tener un empleo, que el Estado y que todo este proceso te va a ofrecer unas condiciones, que dicen bueno, usted cómo es víctima usted va a tener, no diría yo privilegios, pero si a raíz del conflicto y a raíz de toda la situación que ha pasado, usted va a llegar y por lo menos la vamos a tener en cuenta para una ubicación laboral" (Mujer, entrevista \#1, 10 de mayo de 2017).

En el nivel cívico, se busca la restitución y reivindicación de derechos, valoración como igual, tener libertad, dignidad en el trato, leyes justas, garantías y ejercicio del voto; son elementos que confluyen hacia una dignidad que se podría definir como un bien común (Hoyos, 2005) y como proceso de incorporación a una ciudadanía plena. Todo ello está en relación con los marcos jurídicos vigentes (por ejemplo en nuestro caso con la Ley de víctimas y el Acuerdo de paz), así como con todos los mecanismos de aseguramiento de unas condiciones de vida necesarias y democráticas tanto en la sociedad rural o urbana.

"Reivindicación plena y efectiva de los derechos del ser humano, garantía de la víctima en general" (Hombre, entrevista \#9, 02 de junio de 2017). 
"Dignidad tiene que ver con derechos políticos, pero también derechos económicos, sociales y culturales" (Mujer, entrevista \#2, 11 de mayo de 2017).

"El concepto de dignidad es aquel conjunto de elementos que debe enfocarse en la reivindicación plena y efectiva de los derechos del ser humano, la dignidad es inherente a los derechos plenos efectivos del ser humano, por eso lo contrario, la indignidad" (Hombre, entrevista \#9, 02 de junio de 2017).

Pero también la dignidad aparece relacionada con un aspecto del retorno que es la seguridad, que se garantice que no se repita lo vivido a través de asistencia y protección. Dicho aspecto viene a tener gran centralidad debido al alto nivel de violencia que implicó el desplazamiento forzado y en muchos casos la falta de garantías, ya que la desmovilización de las FARC generó que otros actores armados tomaran el control de algunos territorios, e incluso es posible que no todos se hayan desmovilizado. Siendo así pueden ser varias las posibilidades de riesgo que hacen que el retorno se vuelva un proceso de incertidumbre y de fragilidad existencial, por lo que esta característica del retorno digno es una condición que puede resultar de largo plazo en cuanto la estabilización del país frente al proceso de postconflicto.

"La dignidad se relaciona con una política de acompañamiento que pueda garantizar la reinserción en el país en condiciones seguras, en caso de acompañamiento de seguridad personal" (Hombre, entrevista \#10, 10 de junio de 2017).

"La dignidad debemos construirla, digno y garantista, que haya garantías para ese retorno" (Hombre, entrevista \#7, 01 de junio de 2017).

"Si lo miramos ya desde el punto de vista de lo que es la dignidad de la víctima que vive fuera del país, esa dignidad tiene que ver con, y en los acuerdos lo dice, los acuerdos se enfoca mucho en el tema del retorno con dignidad, el retorno asistido, el retorno protegido, ese retorno con dignidad es el todo, y el todo" (Hombre, entrevista \#9, 02 de junio de 2017).

De esta manera podemos observar que las víctimas del conflicto también demandan y ofrecen una definición de dignidad que en gran medida se relaciona con los requisitos básicos para una reintegración justa en una sociedad que los expulsó de manera injusta. En el trasfondo de todas las entrevistas se aprecia un reclamo por reconstruir sus vidas, sin perder de vista la experiencia propia del desplazamiento forzado, ya que esta experiencia es en parte el catalizador de todo el proceso. Los aspectos principales se pueden comprender como los subjetivos, como ruptura de la propia condición moral del ser humano; en la idea del extravío de la dignidad; la búsqueda de la memoria y la experiencia de vida afectada por el desplazamiento forzado; también en las necesidades materiales básicas de subsistencia; así como en la idea de recuperar la ciudadanía y las condiciones democráticas, en donde uno de los aspectos que se requieren para el necesario desarrollo de la dignidad se constituye a partir de la idea de la seguridad, la cual es clave fundamental para el retorno.

\section{Conclusiones}

En este artículo se ha analizado el concepto de dignidad asociado al retorno de las víctimas del conflicto armado en Colombia. Siendo así, por medio del análisis documental, hemos podido ver que dicho concepto ha estado ausente en la normativa migratoria relacionada con el retorno, en el CONPES 3603 de 2009, la Ley 1465 de 2011 y en la Ley 1565 de 2012. Fundamentalmente la dignidad se expresa en la Ley de víctimas, en donde se relaciona con el derecho a la verdad, la justicia y 
la reparación, respeto a la integridad, honra y participación de las víctimas. En el Acuerdo de paz también aparece, con el reconocimiento y reparación de las víctimas en el exterior, acompañamiento y asistencia en el retorno, condiciones que aseguren acceso a derechos básicos, reubicación y medidas para impulsar el regreso. Además habría que agregar, siguiendo las ideas de ACNUR, el buen trato y la no separación de las familias. Los elementos identificados efectivamente van dando significado propio al concepto de la dignidad en el retorno, y deberían ser acompañados para darles operatividad y que no se queden en el papel o en el mero enunciado.

De la misma forma los discursos de las víctimas ofrecen dimensiones que no deben pasar desapercibidas ya que expresan y refuerzan prioridades del retorno digno. Se han identificado cuatro campos semánticos fundamentales en torno a la dignidad. El primero, relacionado con el plano subjetivo, enmarca toda una serie de aspectos sensibles en cuanto al proceso de recuperación de la dignidad, por ejemplo, del reconocimiento y el respeto. El segundo, relacionado con las condiciones materiales y económicas necesarias para la reincorporación a la sociedad, en donde tiene valor el trayecto de vida y la experiencia de los retornados. Y el tercero, que podemos situar en un nivel cívico, tendría que ver con la construcción de la dignidad como un bien común y como el ejercicio de la ciudadanía y la democracia. Finalmente la necesidad de seguridad como factor de sostenibilidad del retorno.

Una de las principales conclusiones a las que se puede llegar es que cada aspecto identificado en este trabajo ofrece una arista de lo que traduce la dignidad en humanidad. Es decir, mientras más digno, el retorno se vuelve más humano. Sin embargo, habrá que matizar la valoración de cada una de sus variables en relación a los niveles políticos nacionales e internacionales, y en los planos culturales y comunitarios, ya que ello puede marcar diferencias incluso dentro de un territorio nacional. Así también contrastar los resultados encontrados en diferentes estudios que puedan aportar a una mayor comprensión de los significados y apropiaciones del concepto.

La recomposición del concepto en busca de una amplia definición se traslada a múltiples desafíos institucionales y personales, tanto de los gobiernos como de los ciudadanos, ya que hay aspectos que no son sólo responsabilidad de las políticas públicas, sino también de la disposición y apertura de las personas en los diferentes niveles de diálogo, acercamiento y reconocimiento entre aquellos que se quedaron y los que se fueron a la fuerza y hoy regresan.

En el proceso investigativo emergen una serie de interrogantes sobre los caminos a seguir en la construcción de una dignidad en el retorno, vinculados con los elementos identificados. Entre ellos el cómo conocer y dar a conocer los proyectos de vida de los retornados, para que la sociedad colombiana pueda acercarse a las diferentes verdades que envuelven el proceso de construcción de paz; la visibilización de los daños cometidos; y conocer el relato de los protagonistas y sus sufrimientos. En ese sentido es importante identificar cuáles son los elementos necesarios para una reparación moral efectiva. Hay que generar estrategias concretas para lograr el perdón y el reconocimiento por el exilio, así como rescatar la memoria de las víctimas en el exterior.

Hay una serie de debates abiertos que se desprenden de esta investigación, y que aún son un camino por avanzar. Entre ellos destacamos, por ejemplo, cómo evitar el estigma frente al retorno, ya que las personas que lo protagonizan pueden ser vistas con sospecha. Pero también la verificación de que los retornados estén viviendo en condiciones "decentes", cuestión que requiere ser evaluada, para analizar cuáles son las condiciones de vida necesarias para que un retornado sienta que ha recuperado 
su dignidad. Para ello sería importante contar con un seguimiento para evaluar la restitución de derechos y cumplimiento de la justicia, conocer cómo están siendo tratados y observar si el proceso se está garantizado. Es prioritario verificar que las condiciones de satisfacción de necesidades básicas se estén cumpliendo frente a una vida material digna. Finalmente realizar vigilancia sobre si el retorno ofrece las condiciones de seguridad necesarias, ante lo cual se deben facilitar mecanismos de denuncia y de asistencia permanente en caso de presentarse algún incidente.

\section{Bibliografía}

Aguiló, A. (2009), "Los derechos humanos como campo de luchas por la diversidad humana: un análisis desde la sociología crítica de Boaventura de Sousa Santos". Universitas humanística. Vol. 69, n 68, pp. 179-205 [artículo en línea]. [Fecha de consulta: 13/05/2017]. <http://revistas.javeriana.edu.co/index.php/univhumanistica/ article/view/2272>

Aliaga, F.; Uribe, C.; Blanco, J.; Ballén, A.; Robayo, I. (2017). Imaginarios del retorno a Colombia posconflicto. Discursos de colombianos refugiados en Ecuador. Digithum. $N^{\circ} 20$, pp. 1-13 [artículo en línea]. [Fecha de consulta: 13/08/2017] <https://digithum. uoc.edu/ articles/abstract/3097/>

Alto Comisionado de las Naciones Unidas para los Refugiados (ACNUR). (2017a). Tendencias globales. Desplazamiento forzado en 2016 [informe en línea]. [Fecha de consulta: 05/01/2017]. <http://www.acnur.org/recursos/estadisticas/tendencias-globales-2016/>

Alto Comisionado de las Naciones Unidas para los Refugiados (ACNUR). (2017b). Actualización de la Situación Colombia [informe en línea]. [Fecha de consulta: 08/01/2017]. <http://www.acnur.org/fileadmin/scripts/doc. php?file=fileadmin/Documentos/ BDL/2017/10938>

Alto Comisionado de las Naciones Unidas para los Refugiados (2015). Tendencias globales del desplazamiento forzado en 2015. Forzados a Huir. Ginebra: ACNUR [informe en línea]. [Fecha de consulta: 10/04/2017] <http://www.acnur.org/t3/fileadmin/Documentos/Publicaciones/2016/10627.pdf>

Alto Comisionado de las Naciones Unidas para los Refugiados (ACNUR). (2011) Manual de Reasentamiento del ACNUR [informe en línea]. [Fecha de consulta: 05/06/2017]. <http://www.acnur.org/fileadmin/scripts/doc.php?file=fileadmin/Documentos/ Publicaciones/2013/9138>

Alto Comisionado de las Naciones Unidas para los Refugiados (ACNUR). (1996). Manual repatriación voluntaria: protección internacional. Ginebra: ACNUR [informe en línea]. [Fecha de consulta: 05/06/2017]. <http://www.acnur.es/PDF/7742_20120508173844. pdf>

Bedoya, M. (2015). El papel de las políticas públicas de migración y retorno en Colombia en el marco de la crisis económica mundial: los casos del Eje Cafetero, Cali, Medellín y Bogotá. Estudios Políticos, n 46, pp. 79-99 [artículo en línea]. [Fecha de consulta: 13/06/2017]. <http://www.redalyc.org/articulo.oa?id=16433765005>

Bohórquez, V.; Aguirre, J. (2009). Las tensiones de la dignidad humana: conceptualización y aplicación en el derecho internacional de los derechos humanos. SUR, Vol. 6, n 11, pp. 41-63 [artículo en línea]. [Fecha de consulta: 15/01/2017]. <http://www. corteidh.or.cr/tablas/r24903.pdf> 
Cancillería de Colombia (2017). Reunión Grupo Académico de la Comisión Intersectorial para el Retorno. Bogotá: Programa Colombia Nos Une [presentación en línea]. [Fecha de consulta: 20/06/2017]. <https://cercomision.files.wordpress.com/2018/01/presentacic3b3n-grupo-acadc3a9mico-marzo-2017.pdf>

Colombia. Congreso de la República y FARC-EP. (2016). Acuerdo final para la terminación del conflicto y la construcción de una paz duradera [informe en línea]. [Fecha de consulta: 15/02/2017]. <http://www.acuerdodepaz.gov.co/>

Colombia. Congreso De La República (2012). Ley 1565. Por medio de la cual se dictan disposiciones y se fijan incentivos para el retorno de los colombianos residentes en el extranjero [normativa en línea]. [Fecha de consulta: 10/02/2017]. <http://www. mintrabajo.gov.co/component/docman/doc_download/1272-Ley-1565-del-31-de-juliode-2012.html>

Colombia. Congreso De La República (2011). Ley 1448. Por la cual se dictan medidas de atención, asistencia y reparación integral a las víctimas del conflicto armado interno y se dictan otras disposiciones. Diario Oficial. 10 de junio de 2011. No. 48.096 [normativa en línea]. [Fecha de consulta: 10/02/2017]. <http://www.secretariasenado.gov.co/ senado/basedoc/Ley_1448_2011.html>

Colombia. Congreso De La República (2011). Ley 1465. Por medio de la cual se crea el Sistema Nacional de Migraciones. Diario Oficial. 30 de junio de 2011. No. 48.116 [normativa en línea]. [Fecha de consulta: 10/02/2017]. <http://www.secretariasenado.gov. co/senado/basedoc/Ley_1465_2011.html>

Colombia. Departamento Nacional De Planeación. (2010). Plan Nacional de Desarrollo 2010-2014. Prosperidad para todos [informe en línea]. [Fecha de consulta: 15/03/2017]. <https://www.dnp.gov.co/Plan-Nacional-de-Desarrollo/PND-2010-2014/ Paginas/Plan-Nacional-De-2010-2014.aspx>

Colombia. Cancillería. (2009). Documento CONPES de Política Integral Migratoria-CONPES 3603 [informe en línea]. [Fecha de consulta: 15/03/2017]. <https://issuu.com/ territorioyhabitat/docs/CONPES_3603_-_poltica_integral_migr>

Colombia. Departamento Nacional de Planeación (DNP). (2005). Visión Colombia II Centenario: 2019. Bogotá, D. C.: Planeta [informe en línea]. [Fecha de consulta: 15/03/2017]. <https://www.dnp.gov.co/politicas-de-estado/vision-colombia-2019/Paginas/programa-vision-colombia-2019.aspx>

Colombia. Asamblea Nacional Constituyente (1991). Constitución Política [normativa en línea]. [Fecha de consulta: 10/02/2017]. <http://www.alcaldiabogota.gov.co/sisjur/normas/Norma1.jsp?i=4125>

Consultoría para los Derechos Humanos y el Desplazamiento - CODHES (2017). Mapeo de connacionales en el exterior víctimas del conflicto armado colombiano. Caracterización de los contextos generales de las personas colombianas que han sido víctimas del conflicto armado en Colombia. Papeles para la Incidencia No. 7 [informe en línea]. [Fecha de consulta: 10/05/2017]. <http://codhes.org/images/Papeles_para_la_incidencia_7_2_Connacionales.pdf>

De Lucas, J. (2010). Naturaleza y dignidad humana. Mètode: Revista de difusión de la Investigación, 67, 70-75 [artículo en línea]. [Fecha de consulta: 13/07/2017]. <http:// metode.es/revistas-metode/monograficos/naturaleza-y-dignidad-humana.html> 
Delgado, R. (2014). Globalización neoliberal y migración forzada: una mirada desde el sur. En: Blanco, C. Movilidad humana y diversidad social en un contexto de crisis económica internacional. Pp. 31-50. Madrid: Trotta.

Echeverri, M. \& Pavajeau, C. (2015). El sujeto del retorno en Colombia. Entre políticas, Leyes y trayectorias de resistencia de la población migrante retornada. Mondi Migranti. Rivista di studi e ricerche sulle migrazioni internazionali, n 3 , pp. 83-104.

Gándara, M. (2014). Repensando los derechos humanos desde las luchas, Revista Culturas Jurídicas, 2014, núm.1, pp.75-90 [artículo en línea]. [Fecha de consulta: 13/06/2017]. <http://www.culturasjuridicas.uff.br/index.php/rcj/article/view/88>

Habermas, J. (2010). El concepto de dignidad humana y la utopía realista de los derechos humanos. Diánoia. Vol. LV, n 64, pp. 3-25. [artículo en línea]. [Fecha de consulta: 15/02/2017]. <http://www.scielo.org.mx/pdf/dianoia/v55n64/v55n64a1.pdf>

Herrera, J. (2005). Los derechos humanos como productos culturales. Crítica del humanismo abstracto. Madrid: Catarata.

Hoyos, I. (2005). De la dignidad y de los derechos humanos. Bogotá: Editorial Temis/ Universidad de la Sabana.

Instituto de Políticas Públicas en Derechos Humanos (IPPDH) del MERCOSUR \& Oficina Regional de la OIM para América del Sur (2017). Derechos humanos de personas migrantes. Manual Regional [informe en línea]. [Fecha de consulta: 15/07/2017]. <http:// www.ippdh.mercosur.int/wp-content/uploads/2017/06/Version-web-Manual-Derechoshumanos-de-personas-migrantes.pdf>

Michelini, D. (2010), "Dignidad humana en Kant y Habermas". Revista anual de la Unidad de Historiografía e Historia de las Ideas. Vol. 12, $\mathrm{n}^{\circ}$ 1, pp. 41-49 [artículo en línea]. [Fecha de consulta: 10/02/2017]. <http://www.scielo.org.ar/pdf/efphi/v12n1/v12n1a03. pdf>

Naciones Unidas (1948). Declaración Universal de Derechos Humanos [informe en línea]. [Fecha de consulta: 15/02/2017]. <http://www.un.org/es/ universal-declaration-human-rights/>

Organización Internacional para las Migraciones (2015). Informe sobre las Migraciones en el Mundo. Los migrantes y las ciudades: Nuevas colaboraciones para gestionar la movilidad. Ginebra: OIM [informe en línea]. [Fecha de consulta: 10/04/2017] <http:// www.acnur.org/t3/fileadmin/Documentos/Publicaciones/2016/10627.pdf>

Prieto, V. (2015). Recomendaciones de política para reinserción laboral de los retornados en Colombia (Informe). Bogotá: OIM y el Ministerio de Trabajo en Colombia [informe en línea]. [Fecha de consulta: 10/04/2017] <https://cercomision.files.wordpress. com/2018/01/insercic3b3n-laboral-retornados.pdf>

Santos, B. (1998). Hacia una concepción multicultural de los derechos humanos, En: Santos, B. De la mano de Alicia: lo social y lo político en la postmodernidad (pp.345-352). Bogotá: Siglo del Hombre Editores/Facultad de Derecho Universidad de los Andes.

Santos, B. (2014). Derechos humanos, democracia y desarrollo. Bogotá: Centro de Estudios de Derecho, Justicia y Sociedad. 